\title{
Achieving International Species Conservation Targets: Closing the Gap between Top-Down and Bottom-Up Approaches
}

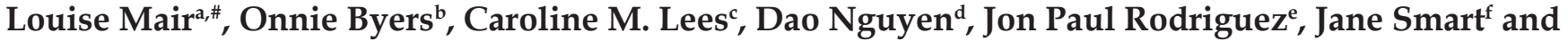 Philip J. K. McGowan'}

\author{
${ }^{\mathrm{a}, \mathrm{g}}$ School of Natural and Environmental Sciences, Newcastle University, Newcastle upon Tyne, United Kingdom
}

bIUCN SSC Conservation Planning Specialist Group, Minneapolis, USA

'IUCN SSC Conservation Planning Specialist Group, Auckland, New Zealand

d,f IUCN, Gland, Switzerland

'IUCN Species Survival Commission, Provita, and Center for Ecology, Venezuelan Institute for Scientific Investigation, Caracas, Venezuela

\#Corresponding author. E-mail: louise.mair@newcastle.ac.uk

\begin{abstract}
In 2010, the Convention on Biological Diversity (CBD) outlined an international strategic plan, which included the twenty Aichi Biodiversity Targets to be met by 2020. Target 12 refers to preventing extinctions and halting species declines. Despite some local conservation successes, this target is not on track to be met at the global level. We aimed to understand what is needed to achieve this target according to two invested but contrasting groups: species conservation experts and global conservation policy makers. We surveyed a diversity of species conservation experts and contrasted their views with those of policy makers engaged with CBD. Species experts considered that the greatest need was for increased political will, while policy makers most frequently cited the need for increased knowledge of species conservation status. Both groups did, however, emphasise that achieving species conservation targets requires greater progress to be made towards many of the other Aichi Targets. We suggest that improved communication, collaboration and data sharing among institutions should be a priority to help overcome the perceived knowledge-gap. Doing so could help to align the views of practitioners and policy makers, and develop a shared understanding of the key actions needed to accelerate progress towards global biodiversity targets.
\end{abstract}

Keywords: Aichi Biodiversity Targets, Convention on Biological Diversity, Target 12, conservation planning, biodiversity conservation, species extinction, international policy

\section{INTRODUCTION}

In 2010, the Convention on Biological Diversity (CBD) adopted the Strategic Plan for Biodiversity 2011-2020 (CBD

\begin{tabular}{|l|l|}
\hline \multicolumn{2}{|c|}{ Access this article online } \\
\hline Quick Response Code: & Website: \\
\hline & www.conservationandsociety.org \\
\cline { 1 - 2 } & \\
\cline { 2 - 2 } & \\
\hline
\end{tabular}

2010). This included twenty Biodiversity Targets, named the 'Aichi Targets' after the location where they were negotiated, which 196 Parties (195 countries and the EU) committed to achieving by 2020 . Aichi Target 12 refers specifically to the conservation of threatened species, and states that "By 2020 the extinction of known threatened species has been prevented and their conservation status, particularly of those most in decline, has been improved and sustained" (CBD 2010). Despite some local species conservation successes (e.g. Hoffmann et al. 2010; Hoffmann et al. 2015; Jones et al. 2016), this ambitious target is not on track to be met at the global level (CBD 2014; Tittensor et al. 2014; IPBES 2019). Instead, species extinctions continue to occur and the conservation status of

Copyright: (C) Mair et al. 2020. This is an open access article distributed under the terms of the Creative Commons Attribution License, which permits unrestricted use and distribution of the article, provided the original work is cited. Published by Wolters Kluwer - Medknow, Mumbai | Managed and supported by the Ashoka Trust for Research in Ecology and the Environment (ATREE), Bangalore. For reprints contact: reprints@medknow.com 
threatened species continues to decline (Ceballos et al. 2017; Woinarski et al. 2017). It is therefore essential to increase our understanding of what is needed to improve progress towards this target and, moreover, to improve threatened species' conservation status beyond 2020 .

While there is a huge amount of research into individual species and diverse aspects of species conservation, research in the scientific literature specific to Target 12 is surprisingly limited, with the majority of research into the Aichi Targets focussing on Target 11 (the protected areas target; Green et al. 2019). High-level recommendations on how to approach and achieve Target 12 as a policy target therefore come primarily from documents produced either by or for CBD. In these documents, emphasis is given to determining the conservation status of species and the development, implementation and monitoring of species recovery plans (CBD 2015). Other actions such as identifying and protecting sites that are important for biodiversity, and tackling broad scale issues, such as unsustainable agriculture, forestry and fisheries, through policy responses are also recommended (CBD 2015). The recommendation of a broad suite of actions highlights that the achievement of Target 12 is dependent upon the achievement of most, if not all, of the other Aichi Targets (CBD 2016g). The inter-dependency of Target 12 has also been recognised in the scientific literature, with Marques et al. (2014) identifying Target 12 as having the most 'upstream interactions', meaning that action taken for many other targets also influences the attainment of Target 12 .

Given the paucity of scientific literature specific to Target 12, and the diversity of actions required for conserving species, obtaining a broad-scale synthesise of what is needed to improve progress towards the target is challenging. One useful approach is to elicit the opinion of experts. This approach has been used in different ways to address a range of complex issues in ecology and conservation (e.g. Harris et al. 2015; Swan et al. 2017), particularly in situations facing limitations due to lack of data, or in evaluating mainly qualitative data (Martin et al. 2012). There is arguably a diversity of experts that could be consulted on the implementation of species conservation policy, ranging from the conservation practitioners working on the ground, to the policy-makers charged with developing and implementing species conservation policy at the national level. Policy makers shape the national environments within which practitioners work, and so obtaining views from both groups should develop a more comprehensive understanding of the actions needed to make progress towards Aichi Target 12.

This study therefore aims to draw upon the experience and knowledge of species conservation experts and contrast this with the views of policy-makers, in order to understand differing perspectives on what is needed to accelerate progress towards Target 12 and whatever replaces it in the post-2020 Global Biodiversity Framework presently being negotiated. We surveyed a diversity of species conservation experts from across the globe, and compared their responses with information gathered from policy makers during a series of CBD regional capacity-building workshops. Regional workshops were carried out specifically to support national progress towards Target 12, which the CBD Secretariat recognised had been limited (CBD 2012). Our objectives were to - 1 ) identify the relative need for different actions across a range of scales, from governmental involvement to planning for on the ground action, according to species conservation experts; and 2) contrast this with the views expressed by CBD focal points (the policy makers whose national role it is to engage with $\mathrm{CBD}$ ) on the national needs for making progress towards Target 12 .

\section{MATERIALS AND METHODS}

\section{Survey development}

The survey was designed to elicit responses on the need for actions and outcomes that could potentially accelerate progress towards Target 12 . We identified a range of potential actions and outcomes using a scoping exercise carried out during a workshop at the IUCN's Species Survival Commission Conservation Planning Specialist Group (CPSG) annual meeting 2017. The CPSG workshop participants were asked to identify limitations in achieving species conservation. We distilled the responses from these sources into a range of actions and outcomes that were then organised into four themes: government and political issues; social and public engagement; resources and funding; and conservation planning. Additional questions were incorporated based on direct input from species conservation and policy experts in order to ensure that a full complement of issues were addressed while balancing the necessity for the survey to be concise.

Survey participants were asked to answer questions thinking specifically about the situation in the country in which they worked. Participants were asked to consider actions or outcomes within each theme simultaneously, and rate the need for these as "Extreme need", "Strong need", "Some need", "Already adequate", or "Not relevant for species conservation". A multiple-choice format was used to maximise response rate by keeping the survey short (Vicente and Reis 2010), and to increase the ease and objectivity of analysis. In order to capture other actions or outcomes not considered in the survey, a free text question was included asking if the respondent had any other ideas for what could be done to improve species conservation.

In order to assess regional differences, participants were asked to state the country in which they worked. To gain an understanding of the diversity of expertise and experience in responses, participants were also asked about their work experience, knowledge of the CBD and membership of SSC specialist groups.

\section{Survey distribution}

A pilot survey was sent to a representative sample of 15 species conservation experts, who were members of IUCN's Species Survival Commission (SSC). Eight responses were received 
and the content and structure of the survey was considered effective.

The final survey was then made available in three languages (English, Spanish and French). An email was sent to the ca. 6,750 members of SSC asking them to complete the online survey. The survey was open for 19 days between April 26 to May 14, 2018.

\section{Analysis of multiple-choice responses}

We compared the relative need for potential actions or outcomes using the percentage of respondents that selected 'extreme need', as this response indicates an action that can be considered essential to achieving Target 12 . Need may be expected to differ among the broad themes; for example, participants may generally consider there to be a greater need for actions or outcomes within Resources and Funding compared to those within Social and Public Engagement. In order to test for a difference between pairs of themes in the perceived need, we used Mann-Whitney U-tests to test for a significant difference in the percent extreme need per action. In order to ensure that results were robust to variation among participants in their interpretation of 'extreme need', we repeated the analyses using the total percent that selected either 'strong need' or 'extreme need' per action.

Given that the distribution of biodiversity, wealth and conservation spending varies geographically (Waldron et al. 2013), we would expect there to be a difference among geographic regions and socio-economic status in the need for potential actions. We used five different approaches to grouping countries to test for differences among geo-political regions, biogeographic regions, and socio-economic status. These groupings were - 1) the five global regions used by the Intergovernmental Science-Policy Platform on Biodiversity and Ecosystem Services (IPBES; www.ipbes.net/members); 2) the eight biogeographic regions used by WWF, as identified by Olson et al (2001); 3) the four income group categories used by the World Bank for the year 2018 (World Bank 2019a); 4) four groups created using quartiles of the Government Effectiveness indicator, which is one of six World Governance Indicators (World Bank 2019b), for the year 2018; and 5) four groups created using quartiles of estimates of population density for the year 2018 from the World Bank (World Bank 2019c). In each case, we used Chi-squared tests to compare the proportion of respondents that selected extreme need against group, conducting one test for each action or outcome. For the IPBES regions, we repeated analyses using the proportion of respondents that selected either 'strong need' or 'extreme need'.

\section{Analyses of free text responses}

The free text responses to other ideas for improving species conservation were summarised manually. In order to achieve a balance between the specificity provided by respondents and the necessity to generalise to provide a summary, responses were classified into 85 categories. These categories were then grouped into the four themes presented in the survey. This gave a large number of categories per theme, and so sub-themes were used to group similar categories (for example the categories "engage academia", "engage NGOs" and "engage zoos" were all grouped into the sub-theme "engage other sectors"). The aim was to provide an overview of the diversity of suggestions and in particular to identify needs that were not included in the survey response options.

\section{CBD regional workshops}

A series of regional capacity-building workshops were held by the CBD Secretariat to gather and share information on the actions that were being undertaken, and that were still needed, to achieve Targets 11 and 12 (CBD 2016a,b,c,d,e,f). A total of six regional workshops were conducted, one each in Africa, East and South-East Asia, South, Central and West Asia, Central and Eastern Europe, Latin America and the Caribbean, and the Pacific. Workshop participants were asked to provide details on actions being taken towards achieving Target 12 in their country, and to identify gaps, opportunities and priority actions for progress. These responses provided insights into the constraints that countries face and what they consider is needed to make progress towards Target 12 .

In order to condense and simplify information, the responses from countries participating in the six workshops were collated into 38 categories. Where appropriate, the same categories as used in the survey were applied, but some expansion of categories was required to fully capture the range of responses. These categories were organised into the same four themes as the survey responses. In some cases, the information provided reflected threats, rather than limitations or actions needed to overcome threats e.g. "pressures from habitat loss" or "challenges to biodiversity from climate change" are threats, whereas "lack of financial support" is a limitation to tackling these threats. Threats were therefore not included in the analysis.

Response data were not quantitative as workshop participants were not given options to choose from and instead could provide responses ad libitum. Focal point response rates to requests from the CBD Secretariat can be low (e.g. 64 countries giving a response rate of $32 \%$; CBD 2018a) resulting in a relative paucity of data when the aim is to achieve a global overview. The availability of data following these regional workshops was therefore relatively good, and responses capture Parties' understanding of the actions required for Target 12. We present data on the number of countries that identified each need, with the explicit recognition that these data are not rigorously collected and therefore do not provide an absolute quantitative analysis. Results nevertheless provide a valuable, qualitative insight into the perspectives of policymakers.

\section{RESULTS}

\section{Composition of survey respondents}

Nine-hundred responses were received from across 134 countries $(\sim 13 \%$ response rate). The largest number of 
responses were from those working in the USA $(9.2 \%)$, followed by India (6.5\%), UK (3.4\%), Brazil (3.3\%) and Australia (3.1\%; Table S1). Grouping countries into IPBES global regions, the largest number of responses were from those working in Western Europe and other (32.2\%) and the fewest from Eastern Europe (5.0\%; Figure S1a).

The majority of respondents worked in academia or for a non-governmental organisation $(36.7 \%$ and $36.3 \%$ respectively; Figure S1b). Respondents could select multiple areas of expertise, and the most popular was research (22.1\%), followed by in situ conservation (19.3\%) and then conservation planning (13.5\%, Figure S1c). The majority of respondents (92.8\%) were members of at least one of 126 SSC Specialist Groups (SGs).

$7.0 \%$ of respondents were unaware of the CBD, $27.2 \%$ were unaware that Parties to the CBD produced National Biodiversity Strategies and Action Plans, and 48.3\% did not know if there was a national target for species conservation (Figure S1d-f).

\section{Actions and outcomes needed to achieve Target 12}

The vast majority of respondents considered there to be extreme, strong or some need for each action or outcome (mean 95\%, range 85\%-99\% among actions; Figure 1). A small minority of respondents considered actions to be already adequate in the country in which they worked (mean 5\%, range $1 \%-15 \%$ ), and very few respondents considered that actions were not relevant for species conservation (mean $0.5 \%$, range $0.1 \%-1.6 \%)$.

We used the percentage of respondents that selected 'extreme need' as an indication of where there is the greatest need for action. Overall, political will was considered to be of greatest need, with $59.1 \%$ of respondents indicating extreme need
(Figure 2). This was closely followed by increasing value placed on nature by society $(52.9 \%)$, greater understanding of the positive relationship between conservation and human wellbeing by society $(52.5 \%)$, greater enforcement of legislation relevant to species conservation $(52.2 \%)$, and increased government funding for species conservation (52.1\%- Figure 2).

Actions within the theme of Government and Political Issues had the greatest spread in perceived need (mean percent of respondents selecting 'extreme need' $37.1 \%$, range $21.2 \%$ $59.1 \%$ - Figure 2 ) and as a result the percentage of respondents that selected extreme need was not significantly different to Social and Public Engagement, Resources and Funding or Conservation Planning (Mann-Whitney U tests, $P>0.3$ in all cases). The percentage of respondents indicating an extreme need for actions within Social and Public Engagement did not differ significantly from Resources and Funding (engagement: mean $46.0 \%$, range $39.5 \%-52.9 \%$; resources: mean $44.1 \%$, range $39.8 \%-52.1 \% ; P=0.6$ ), however both were significantly higher than the percentage of respondents that indicated extreme need for Conservation Planning actions (mean 30.2\%, range $17.3 \%-42.1 \% ; P=0.002$ in both cases; Figure 2 ). When the analyses were repeated using the percentage of respondents that selected either 'strong need' or 'extreme need', the results were qualitatively the same (Table S2).

\section{Regional variations in actions needed}

There was significant variation among IPBES global regions in the percentage of respondents that indicated extreme need for 25 out of the 31 actions (Chi-squared tests, $P<0.05$ in all cases, Table S3 and Figure S2). Actions for which extreme need did not differ significantly among regions were greater political will, increased value placed on nature by society,

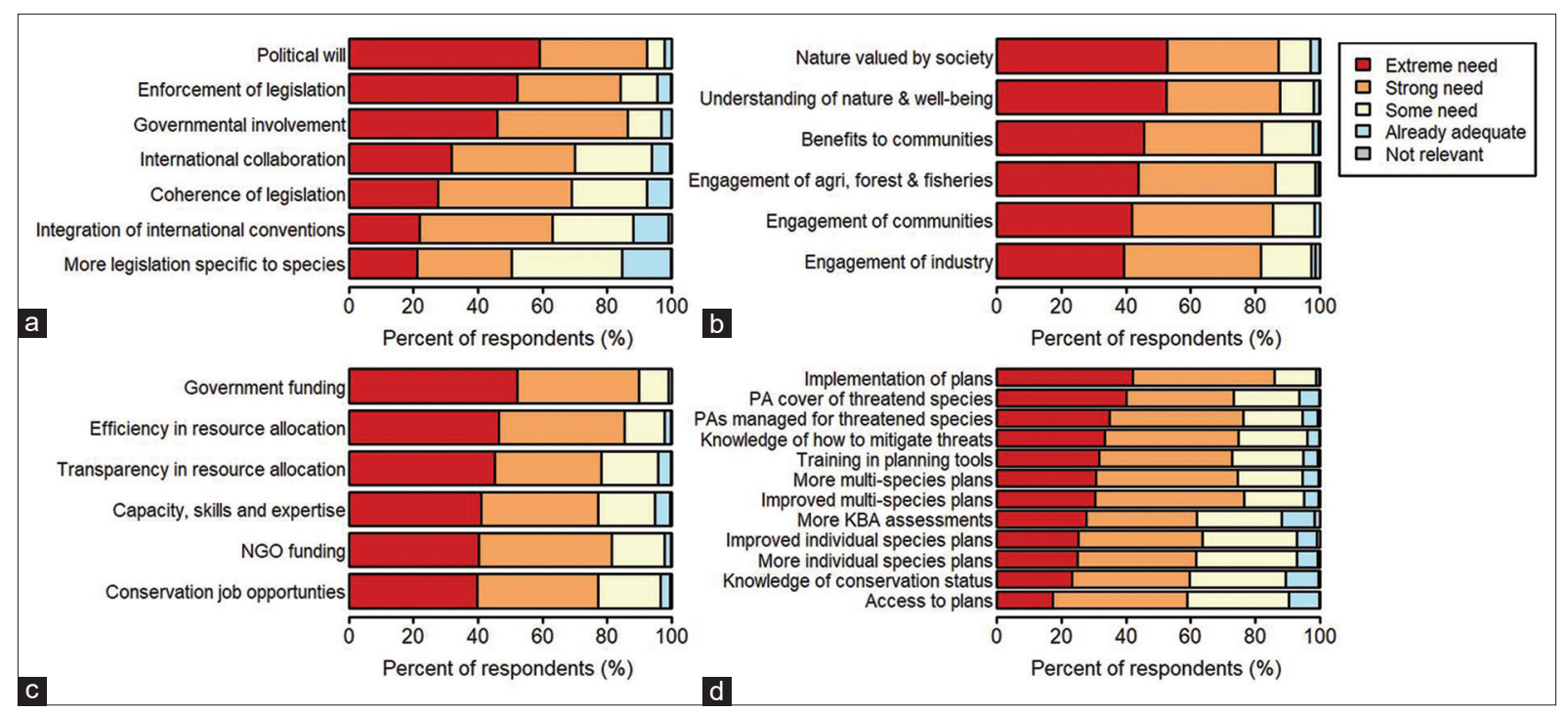

Figure 1

The perceived need for each action or outcome to accelerate progress towards preventing species extinctions and improving the conservation status of species, as percent of responses to the survey of species conservation practitioners. Responses are grouped by themes: (a) Government and political issues; (b) Social and public engagement; (c) Resources and funding; and (d) Conservation planning 


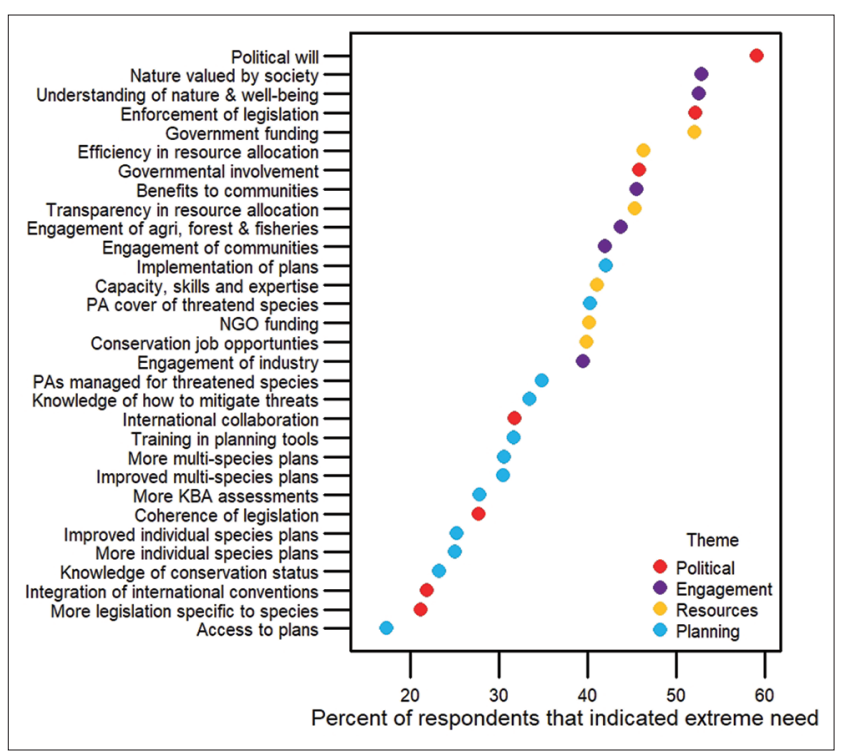

Figure 2

The percent of respondents to the survey of species conservation practitioners that indicated an 'extreme need' for each action or outcome to accelerate progress towards preventing species extinctions and improving the conservation status of species

greater understanding of the positive relationship between conservation and human wellbeing by society, improved international collaboration for species conservation, improved integration of international conventions into national biodiversity policy and more legislation specific to species conservation ( $P>0.1$ in all cases, Table S3 and Figure S2). When the analyses were repeated using the proportion of respondents that selected either 'strong need' or 'extreme need', there were an additional three actions that varied significantly among regions (improved integration of international conventions into national biodiversity policy, more legislation specific to species conservation, and greater understanding of the positive relationship between conservation and human wellbeing by society; $P<0.05$ in all cases, Table S3 and Figure S2) and two actions that were no longer significantly different among regions (increased government funding for species conservation and more multi-species plans; $P>0.05$ in both cases, Table S3 and Figure S2).

There was significant variation among biogeographic realms in the percentage of respondents that indicated extreme need for 22 out of the 31 actions (Chi-squared tests, $P<0.05$ in all cases, Table S4 and Figure S3). Variation was significant among income groups for 21 out of the 31 actions and among government effectiveness indicator quartiles for 23 out of the 31 actions (Chi-squared tests, $P<0.05$ in all cases, Table S4 and Figure S3). Across these three groupings, there were 18 actions in common that showed significant variation; there tended to be a larger percentage of respondents indicating extreme need for actions among those working in countries in the Neotropic realm, countries that were low income, and countries that scored low for government effectiveness (Figure S3). There was significant variation among population density quartiles in the percentage of respondents that indicated extreme need for only 8 out of the 31 actions (Chi-squared tests, $P<0.05$ in all cases, Table S4 and Figure S3).

\section{Other actions identified by respondents}

577 survey respondents provided ideas for other actions and/ or needs to improve species conservation. More than a third of respondents provided more than one suggestion (the number of suggestions per respondent ranged from one to six, with a median of one).

Suggestions were categorised into the four main themes; $31 \%$ related to Conservation Planning and Action, 28\% to Social and Public Engagement, 26\% to Government and Political Issues, and the remaining $14 \%$ to Resources and Funding. The suggestions relating to Conservation Planning and Action were diverse, and were classified as relating to the conservation planning process ( $26 \%$ of suggestions), the recommendation of particular actions $(25 \%)$, the need for increased knowledge $(21 \%)$, the need to tackle particular threats $(15 \%)$, and suggestions relating specifically to protected areas $(12 \%)$. Suggestions relating to conservation planning largely focussed on the need for conservation to take a broader focus and for planning to take a more holistic approach. Similar sentiments were reflected in other ways, with the need for interdisciplinary work, land-use planning, and more comprehensive plans to reduce widespread threats also indicated.

\section{CBD workshop responses}

There were a total of 123 countries with representatives at the six regional CBD workshops. Of these, 97 submitted information to the Secretariat on gaps, opportunities and actions for Target 12, and one additional country (Myanmar) submitted information without attending a workshop. The 98 countries included in the analysis are listed in Table S5 in the Appendix.

The amount of information provided varied among countries. The majority of countries identified two or three actions or outcomes that were required for Target 12, although eight countries identified eight or more (Figure S4). The frequency with which actions or outcomes were identified by CBD workshop participants contrasted with the need for actions identified by the survey of practitioners. The needs most frequently identified by policy makers were related to conservation planning. Within this category, the need for knowledge of species conservation status was the most frequently noted, followed by the need for action plans, the implementation of plans and monitoring (Figure 3 ). The next more frequently identified need was for funding. The need for greater political will was identified by only three countries, and for nature to be valued by society by only one (Figure 3 ).

Within the category of need for knowledge of species conservation status, policymakers stated, for example, that assessments of threatened species were not complete or had not been recently updated. Some specifically referred to the lack 


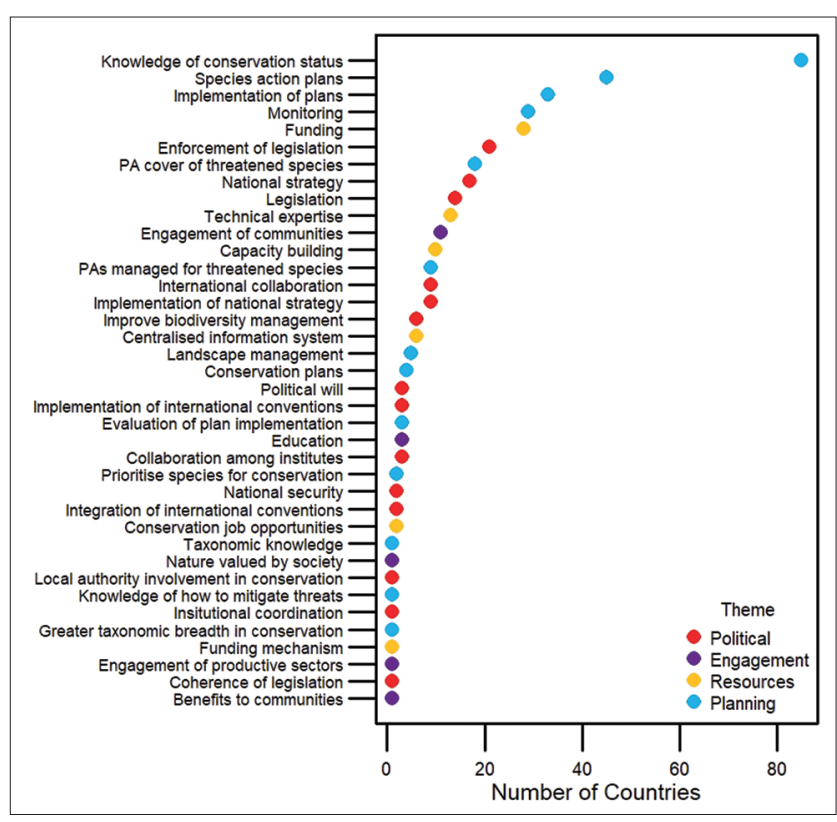

Figure 3

The number of countries that identified each action or outcome as necessary within their country to make progress towards Aichi Target 12 , in response to the information gathering exercise conducted at $C B D$ regional workshops. The actions and outcomes are an adaptation and expansion of those used in the survey of practitioners, and are organised into the same four themes

of national assessments, while some stated that assessments were missing for particular taxa such as plants or invertebrates.

\section{DISCUSSION}

The conservation status of species is declining globally (Ceballos et al. 2017; IPBES 2019), and both species conservation experts and policy makers highlighted that a diverse range of actions are required to prevent further declines and extinctions, and improve progress towards international conservation targets. There appears, however, to be a substantial difference between the two groups in where they consider the greatest needs to lie. Species conservation experts considered the greatest needs to be socio-political, in particular highlighting the need for increased political will and public support, while the need most frequently identified by policy makers was for increased knowledge of species conservation status. It appears, therefore, that there may be a gulf between practitioners and policy makers in terms of their understanding of species conservation needs.

There are several potential underlying drivers of these differences of opinion, and in interpreting the results, it is necessary to bear in mind the context within which information was gathered from CBD workshop participants. The need for greater progress towards Target 12 had been recognised by the CBD Secretariat, and the workshops aimed to assist Parties with identifying priority actions. National CBD focal points are given direction in CBD documents on how to achieve Target 12, and workshop participants' responses were therefore framed within the advice already received from the Secretariat.
As a result, some issues may not have been considered. The data collected nevertheless provide valuable insights into how Parties approach implementation of Target 12 and the actions that they consider priorities for species conservation. Moreover, the specific request for information on 'gaps' in progress towards Target 12 encouraged participants to consider needs that would not necessarily be acknowledged in formal national reporting.

The direction given in CBD documents on how to achieve Target 12 most often consists of advice to conduct Red List assessments of species, and develop and implement species action plans (see for example CBD 2015). It is therefore unsurprising that these actions are the most frequently cited needs from the CBD workshop participants. It is noteworthy, however, that some workshop participants referred specifically to a lack of data, or lack of up-to-date data, at the national level. This suggests that policymakers may perceive global data sources as unsuitable for meeting their national needs. In contrast to policymakers, species experts placed the need for increased knowledge of conservation status as relatively low, suggesting that generally they feel that sufficient information is available to act upon. While the issue of global versus national data may play a role in explaining this dichotomy in opinion, it may also be in part due to a lack of communication and data sharing. This hypothesis is supported by the suggestion from some policy makers that there is a need for a centralised information system or data centre and for increased collaboration among institutes, while species experts considered there to be a relatively strong need for the involvement of government. It appears, therefore, that there has been slow progress in addressing the challenges of national and international cooperation for information sharing and capacity building, and indeed, it may be data-sharing at the national level that is most crucial for meeting the needs of policymakers. These challenges were identified almost ten years ago by Chandra and Idrisova (2011) who recommended that informationsharing mechanisms be put in place to support developing countries and transition economies. Chandra and Idrisova identified the Global Environment Facility's Small Grants Program as a good example of a national institutional coordination mechanism, suggesting that existing programs can be effective but may not be as widely implemented and well-funded as necessary.

Species experts were unanimous among global regions in their consideration that there is an extreme need for greater political will. The need recognised by practitioners for political buy-in ties in closely with the evolving dialogue within CBD of the need for transformational change. Transformational change involves changes in behaviour across all levels of society, including government, in order to create an 'enabling environment' for positive change (CBD 2018b). Yet the need for increased political will was acknowledged by only three national representatives at the $\mathrm{CBD}$ workshops. It may be that policy makers engaged with $\mathrm{CBD}$ are indeed motivated and therefore do not consider there to be a lack of political 
will. Alternatively, national focal points may be unwilling to make comments that could be perceived as a criticism of the political situation in their own countries. In any case, the fact that thirty-one countries did identify the need for a national strategy for species conservation implies a more subtly expressed recognition of the need for greater government buy-in and leadership in conservation. Thus, while the language used may differ, there does appear to be an implicit acknowledgement among policy-makers of the need for greater political engagement, and indeed some Parties to the CBD have acknowledged lack of political will as a barrier to convention implementation in their national reports (Chandra and Idrisova 2011).

There were similarities between species conservation experts and policy makers in some of the needs identified. Both groups considered there to be a need for greater enforcement of legislation, further emphasising the responsibility that governments have for species conservation. Both groups also indicated the need for increased funding for species conservation, which is a widely acknowledge shortfall (McCarthy et al. 2012). The diversity of required actions and outcomes suggested by both groups, such as the need for engagement of communities and of industrial sectors, and the important role of protected areas in species conservation, support our understanding that many, if not all, of the other Aichi Biodiversity Targets contribute towards and may indeed be essential for achieving Target 12 (Marques et al. 2014; CBD 2016g). Protected areas are an important conservation tool for species (Butchart et al. 2012; Watson et al. 2014), and the contribution of Target 11 (the creation of a protected area network) towards achieving Target 12 is well understood by both scientists and policy makers (Butchart et al. 2012; CBD 2014). Statements from species experts in response to the survey highlighted the need for a broader focus or more holistic approach to species conservation, including some specific suggestions such as land-use planning and more comprehensive plans to reduce widespread threats. Landscape management was a need also recognised by policy makers, indicating that both groups considered that conservation for species should include action to improve the wider environment and tackle diffuse threats (for example, as outlined for Madagascar; Rakotomanana et al. 2013). Survey respondents identified particular threats that should be tackled, including invasive species (which is the focus of Aichi Target 9), negative impacts from agriculture (Aichi Target 7) and deforestation (Aichi Target 5), which are among the major threats to species globally (Maxwell et al. 2016). Relating to societal issues, a suggested need from both groups was increased and improved education, which refers to the role of Target 1 in achieving species conservation targets.

Our study aimed to understand the relative need for different actions for species conservation. A diverse range of actions were considered necessary, and our results highlighted the important role that an 'enabling environment' plays in achieving biodiversity conservation targets and, moreover, that achieving species conservation targets specifically requires greater progress to be made towards many other targets. While socio-political issues emerged as a primary concern for species conservation experts, increased knowledge was most frequently cited by policy makers. We suggest therefore that greater collaboration and information sharing among the diversity of actors involved in species conservation should be a priority in order to overcome this perceived knowledge gap. This need for greater communication was recognised in the establishment of the Intergovernmental science-policy Platform for Biodiversity and Ecosystem Services (IPBES) in 2012. The Platform has four functions: assessments, knowledge generation, capacity-building, and policy support, and there has been criticism that resources and emphasis has been disproportionately devoted to assessments (Brooks et al. 2014). As IPBES' second work programme begins, it is an ideal opportunity to devote more attention to the other functions of the Platform that will allow for much greater communication between species conservationists and policy officials. Indeed, the IPBES Capacity Building Rolling Plan (see IPBES 2017) seeks to strengthen both national capacities and access to information. These two strategies within the rolling plan are framed specifically within the context of IPBES deliverables, and is clear that enhancing and, where formalising, the opportunities for dialogue and data sharing between scientists and policy officials will ensure that both constituencies improve their shared understanding of challenges and opportunities. Indeed, Strategy 3 in the Rolling Plan (Strengthening national and regional capacities) calls for the establishment of partnerships that will increase, inter alia, the uptake of assessments. National platforms that will enhance shared understanding by diverse stakeholders of the challenges facing, and needs of, species have the potential to play a significant role in addressing the issues identified by the IPBES Global Assessment, which highlighted weak progress towards Aichi Target 12 (IPBES 2019). Given the global spread and areas of focus of IUCN SSC members surveyed here, there seems to be considerable potential for this existing network to play a foundational role in developing such national partnerships.

\section{CONCLUSION}

The challenges faced in species conservation are complex, and a true sense of shared ownership of these challenges is required if they are to be overcome. Target 12 and the other global targets are the responsibility not simply of the signatory governments but of institutions, non-governmental organisations, indigenous people's organisations, and civil society. Identifying species focal points at the national level and within the CBD secretariat, and creating opportunities for these champions to gather and share their experiences, failures and successes, with other responsible entities would not only help to align the views of practitioners and policy makers, but allow development of a shared understanding of actions needed to accelerate progress towards our shared goal of reversing the biodiversity crisis. 
8 / Mair, et al.

\section{REFERENCES}

Brooks, T.M., J.F. Lamoreux, and J. Soberón. 2014. IPBES $\neq$ IPCC. Trends in Ecology \& Evolution 29(10): 543-545.

Butchart, S.H.M., J.P.W.Scharlemann, M.I. Evans, S. Quader, S. Aricò, J. Arinaitwe, M. Balman. et al. 2012. Protecting important sites for biodiversity contributes to meeting global conservation targets. PLOS ONE 7(3): e32529.

CBD (Convention on Biological Diversity). 2010. Convention on Biological Diversity: Decision X/2: the strategic plan for biodiversity 2011-2020 and the Aichi biodiversity targets. https://www.cbd.int/decision/ cop/?id=12268. Accessed on June 23, 2017

CBD (Convention on Biological Diversity). 2012. Decision adopted by the Conference of the Parties to the Convention on Biological Diversity at its eleventh meeting. https://www.cbd.int/decision/cop/default. shtml?id=13185. Accessed on June 23, 2017.

CBD (Convention on Biological Diversity). 2014. Global Biodiversity Outlook 4. Montréal. https://www.cbd.int/gbo4/. Accessed on June 13, 2017.

CBD (Convention on Biological Diversity). 2015. Species conservation assessment as an essential element of achieving Aichi Biodiversity Target 12. https://www.cbd.int/kb/record/meetingDocument/105869 ?RecordType $=$ meetingDocument $\&$ Event $=$ SBSTTA-19. Accessed on June 28, 2018.

CBD (Convention on Biological Diversity). 2016a. Report of the capacitybuilding workshop for Africa on achieving Aichi Biodiversity Targets 11 and 12. https://www.cbd.int/doc/meetings/pa/paws-2016-01/official/ paws-2016-01-03-en.pdf. Accessed on September 11, 2017.

CBD (Convention on Biological Diversity). 2016b. Report of the capacitybuilding workshop for Central and Eastern Europe on achieving Aichi Biodiversity Targets 11 and 12. https://www.cbd.int/doc/meetings/pa/ paws-2016-02/official/paws-2016-02-03-en.pdf. Accessed on September $11,2017$.

CBD (Convention on Biological Diversity). 2016c. Report of the capacitybuilding workshop for East and South-East Asia on achieving Aichi Biodiversity Targets 11 and 12. https://www.cbd.int/doc/meetings/pa/ paws-2015-01/official/paws-2015-01-03-en.pdf. Accessed on September 11, 2017.

CBD (Convention on Biological Diversity). 2016d. Report of the capacitybuilding workshop for South, Central and West Asia on achieving Aichi Biodiversity Targets 11 and 12. https://www.cbd.int/doc/meetings/pa/ paws-2015-03/official/paws-2015-03-03-en.pdf. Accessed on September 11, 2017.

CBD (Convention on Biological Diversity). 2016e. Report of the capacitybuilding workshop for the Pacific region on achieving Aichi Biodiversity Targets 11 and 12. https://www.cbd.int/doc/meetings/ecr/ecrws-2016-02/ official/ecrws-2016-02-01-en.pdf. Accessed on September 11, 2017.

CBD (Convention on Biological Diversity). 2016f. Report of the capacity building workshop for Latin America and the Caribbean on achieving Aichi Biodiversity Targets 11 and 12. https://www.cbd.int/doc/meetings/ pa/paws-2015-02/official/paws-2015-02-03-en.pdf. Accessed on September 11, 2017.

CBD (Convention on Biological Diversity). 2016g. Supporting implementation of Aichi Biodiversity Target 12. https://www.cbd.int/kb/record/ meetingDocument/ 111121. Accessed on September 11, 2017.

CBD (Convention on Biological Diversity). 2018a. Review of the experience of holding concurrent meetings of the Conference of the Parties to the Convention and the meetings of the Parties to the Protocols. https:// www.cbd.int/doc/c/2a4e/4a1b/9aa23008d4af76c6e2cf4de8/sbi-02-16add1-en.pdf. Accessed on March 9, 2020.

CBD (Convention on Biological Diversity). 2018b. Executive summary of the report of the second Bogis-Bossey dialogue for biodiversity. https:// www.cbd.int/doc/c/f3ea/73fd/a40b0ec9597f284fcd9cf157/sbi-02-inf35-en.pdf. Accessed on September 11, 2018.

Ceballos, G., P.R. Ehrlich, and R. Dirzo. 2017. Biological annihilation via the ongoing sixth mass extinction signaled by vertebrate population losses and declines. Proceedings of the National Academy of Sciences 114(30): E6089-E6096.

Chandra, A. and A. Idrisova. 2011. Convention on Biological Diversity: a review of national challenges and opportunities for implementation. Biodiversity and Conservation 20: 3295-3316.

Green, E.J., G.M. Buchanan, S.H.M. Butchart, G.M. Chandler, N.D. Burgess, S.L.L Hill and R.D. Gregory. 2019. Relating characteristics of global biodiversity targets to reported progress. Conservation Biology 33: $1360-1369$.

Harris, J.B.C., J.M.H. Green, D.M. Prawiradilaga, X. Giam, Giyanto, D. Hikmatullah, C.A. Putra and D.S. Wilcove. 2015. Using market data and expert opinion to identify overexploited species in the wild bird trade. Biological Conservation 187: 51-60.

Hoffmann, M., J.W. Duckworth, K. Holmes, D.P. Mallon, A.S.L. Rodrigues and S.N. Stuart. 2015. The difference conservation makes to extinction risk of the world's ungulates. Conservation Biology 29: 1303-1313.

Hoffmann, M., C. Hilton-Taylor, A. Angulo, M. Böhm, T.M. Brooks, S.H.M. Butchart, K.E. Carpenter. et al. 2010. The impact of conservation on the status of the world's vertebrates. Science 330(6010): 1503-1509.

IPBES 2017. IPBES-5 Plenary Decision IPBES-5/1: implementation of the first work programme of the platform. https://ipbes.net/document-librarycatalogue/decision-ipbes-51. Accessed on August 28, 2020.

IPBES 2019. Summary for policymakers of the global assessment report on biodiversity and ecosystem services of the intergovernmental Sciencepolicy platform on biodiversity and ecosystem Services (eds. Díaz, S., J. Settele, E.S. Brondízio, H.T. Ngo, M. Guèze, J. Agard. et al). Pp. 56. Bonn, Germany: IPBES secretariat.

Jones, H.P., N.D. Holmes, S.H.M. Butchart, B.R. Tershy, P.J. Kappes, I. Corkery, A. Aguirre-Muñoz. et al. 2016. Invasive mammal eradication on islands results in substantial conservation gains. Proceedings of the National Academy of Sciences of the United States of America 113(15): 4033-4038.

Marques, A., H.M. Pereira, C. Krug, P.W. Leadley, P. Visconti, S.R. Januchowski-Hartley, R.M. Krug. et al. 2014. A framework to identify enabling and urgent actions for the 2020 Aichi Targets. Basic and Applied Ecology 15(8): 633-638.

Martin, T.G., M.A. Burgman, F. Fidler, P.M. Kuhnert, S. Low-Choy, M. McBride, and K. Mengersen. 2012. Eliciting expert knowledge in conservation science. Conservation Biology 26: 29-38.

Maxwell, S., R.A. Fuller, T.M. Brooks and J.E.M. Watson. 2016. The ravages of guns, nets and bulldozers. Nature 536: 143-145.

McCarthy, D.P., P.F. Donald, J.P.W. Scharlemann, G.M. Buchanan, A. Balmford, J.M.H. Green, L.A. Bennun. et al. 2012. Financial costs of meeting global biodiversity conservation targets: current spending and unmet needs. Science 338(6109): 946-949.

Olson, D.M., E. Dinerstein, E.D. Wikramanayake, N.D. Burgess, G.V.N. Powell, E.C. Underwood, et al. 2001. Terrestrial ecoregions of the world: a new map of life on earth: a new global map of terrestrial ecoregions provides an innovative tool for conserving biodiversity. BioScience 51(11): 933-938.

Rakotomanana, H., R.K.B. Jenkins, and J. Ratsimbazafy. 2013. Conservation challenges for Madagascar in the next decade. In: Conservation Biology. Pp. 33-39. Chichester: John Wiley \& Sons, Ltd.

Swan, N., J. Barlow and L. Parry. 2017. Expert elicitation as a method for exploring illegal harvest and trade of wild meat over large spatial scales. Oryx 51(2): 298-304.

Tittensor, D.P., M. Walpole, S.L.L. Hill, D.G. Boyce, G.L. Britten, N.D. Burgess, S.H.M. Butchart, et al. 2014. A mid-term analysis of progress toward international biodiversity targets. Science 346(6206): 241-244.

Vicente, P. and E. Reis. 2010. Using questionnaire design to fight nonresponse bias in web surveys. Social Science Computer Review 28(2): 251-267.

Waldron, A., A.O. Mooers, D.C. Miller, N. Nibbelink, D. Redding, T.S. Kuhn, J.T. Roberts, et al. 2013. Targeting global conservation funding to limit immediate biodiversity declines. Proceedings of the National Academy of Sciences 110(29): 12144-12148. 
Watson, J.E.M., N. Dudley, D.B. Segan, and M. Hockings. 2014. The performance and potential of protected areas. Nature 515: 67-73.

Woinarski, J.C.Z., S.T. Garnett, S.M. Legge, and D.B. Lindenmayer. 2017. The contribution of policy, law, management, research, and advocacy failings to the recent extinctions of three Australian vertebrate species. Conservation Biology 31: 13-23.

World Bank 2019a. World Bank GNI per capita, Atlas method. https://datahelpdesk.worldbank.org/knowledgebase/articles/906519world-bank-country-and-lending-groups. Accessed on August 21, 2020.

World Bank 2019b. Worldwide Governance Indicators, 2019 update. www. govindicators.org. Accessed on August 21, 2020.

World Bank 2019c. Food and Agriculture Organization and World Bank population estimates: Population density (people per sq. $\mathrm{km}$ land area). https://data. worldbank.org/indicator/EN.POP.DNST. Accessed on August 21, 2020.

Received: 30-Oct-2019; Revised: 31-Aug-2020; Accepted: 08-Sep-2020; Published: 26-Nov-2020

\section{LIST OF APPENDICES}

Supplementary Tables and Figures for the survey of conservation practitioners and Supplementary Tables and Figures for the cbd workshop analysis can be accessed at ftp://49.206.244.232/pub/ 